\title{
Fully Flexible, Polymer-based Microwave Devices Part II: Flexible Antennas and Performance Evaluation
}

\author{
Iurii Cherukhin, Si-Ping Gao, Member, IEEE, Yong Xin Guo, Member, IEEE
}

\begin{abstract}
In this work, we have investigated polymer-based flexible antennas from commercial and modified polymers, which are competitive to rigid PCB technology. Classical designs of the patch and bow-tie antennas have been realized and showed that the realized gain can get up to $9.16 \mathrm{dBi}$ for the patch and $7.9 \mathrm{dBi}$ for the bow-tie antennas. The effects of the dielectric loss and conductivity on the antennas' performance in S-band have been analyzed in order to find limits for further material engineering and the optimum trade-off between microwave and mechanical performance. The bending effects have been investigated, and it has been found that E-plane bend inside can boost the antenna gain from 8.6dBi to $10.1 \mathrm{dBi}$ with the frequency shift from 2.5 GHz to $2.4 \mathrm{GHz}$ for the patch and $7.9 \mathrm{dBi}$ to $11.3 \mathrm{dBi}$ at $3.1 \mathrm{GHz}$ for the bow-tie antennas. The non-classical $\pi$-shaped conductors' edges lead to additional fringing fields, which have an effect on the antenna's gain and can be explored and exploited for further performance improvements. The new recipes for low-loss, lowDk dielectric materials and chemical integration between conducting polymers and PDMS have been presented in this work.
\end{abstract}

Index Terms - PDMS, flexible antenna, CPW, patch antenna, bow-tie antenna, conductive polymer, polymer-based, low-loss material.

\section{INTRODUCTION}

$\mathrm{F}$ ULLY flexible polymer-based microwave electronics is a new technology and can find its niche in various applications or extend to the common commercial technologies such as PCB and metal waveguides. The applications of flexible polymer-based microwave electronics can be diverse, from wearable [1], and implantable devices [2], to air-space and defense applications. Mechanical flexibility tolerates harsh endowment conditions, bending, and distortions without the microwave devices' physical

Manuscript received December 9, 2020; revised XXX; This work was supported in part by XXX.

I. Cherukhin is with the Department of Electrical and Computer Engineering, National University of Singapore, 4 Engineering Drive 3, 117583, Singapore (e-mail: $\quad \underline{\text { urii.cherukhin@u.nus.edu; }}$ Iurii.Cherukhin@gmail.com).

S. P. Gao is with the Department of Electrical and Computer Engineering, National University of Singapore, 4 Engineering Drive 3, 117583, Singapore (e-mail: gaosp@nus.edu.sg).

Y. X. Guo is with the Department of Electrical and Computer Engineering, National University of Singapore, 4 Engineering Drive 3, 117583, Singapore (e-mail: yongxin.guo@nus.edu.sg). destruction. This can be used under extreme operational conditions, e.g., rapid acceleration, immense vibrations, various deformations, including twisting, bending, and stretching.

Generally, the flexible microwave electrons can be divided into three groups by types of materials: 1) semi-ridged [3], [4], [5], which are based on very thin Roger, Duroid, or LCP (liquid crystal polymer) substrates with copper cladding; 2) thin-flexible [6], [7], [8], which are based on PEN (polyethylene naphthalate), PET (polyethylene terephthalate) and Kapton (polyimide) and similar rigid polymers with copper cladding or 3D printed Ag-inks; 3) polymer-based [9], [10], which are produced fully or partially from elastomers and can have substrate thickness more than $1 \mathrm{~mm}$ without significant impacts on the flexibility. Most importantly, it allows having unique properties such as self-healing capabilities[11], [12], electro-mechanical actuation [13], [14], etc., which opens new ways for reconfigurability and integration.

The employed fabrication process allows the production of fully flexible polymer-based microwave devices with relatively complex $3 \mathrm{D}$ structures and integration with existing technologies. The mechanical and electrical properties can be adjusted based on the requirements, which gives additional freedom for designs and performance improvements.

Although, the performance of microwave devices is directly related to the materials properties, fabrication process (surface roughness, dimension tolerances), designs, and many other aspects. This work shows that some requirements could be eased or varied to achieve the optimal balance between microwave performance and mechanical flexibility. The first approach to answer this question has been demonstrated in our previous works [15], [16].

In this paper, we continue the investigation of polymerbased microwave devices [17]. The classical designs of a patch antenna and slotted bow-tie antennas have been chosen to evaluate the effect of materials properties, i.e., the dielectric loss and conductivity on antennas performance under flat and bent conditions. The classical design allows looking at the antennas' performance regardless of improvements in designs (improved gain, bandwidth), which, of course, can be implemented on the sequential development steps of flexible polymer-based electronics.

The slotted bow-tie antenna is a wideband antenna and does 
not require any baluns in the feeding network and necessitates only one layer of "metallization". The patch antenna is a resonance-type antenna, where the dielectric loss might have the dominant effect on the performance rather than conductivity. The patch antennas require two layers of "metallization". The different layer configuration has a direct influence on the bending performance. The strain-stress deformation pattern is different in both cases and has different effects on the antenna's mechanical and microwave performance.

\section{MATERIAL, DESIGN AND FABRICATION}

\section{A. Dielectric Elastomers}

The various elastomers have been analyzed, including different PDMS (polydimethylsiloxane) grades, i.e., Sylgard 184, Sylgard 170, MS1002, SE 1740, EG3896, SE 7450 from Dow Chemical, natural latex, elastomers for 3D printing, copolymers, and many others. The results and analysis with selection criteria have been discussed in [17].

Based on the criteria for flexible microwave electronics, a new compound has been developed, which consists of EG3896 PDMS gel, DET or 3M microspheres, and other components.

The combination of EG-3896 and microspheres has unique microwave and mechanical properties, e.g., excellent stretchability, low dielectric loss, low dielectric constant, moisture absorption less than $0.067 \%$, vibration-damping capabilities, etc. Fig. 1 shows the comparison Sylgard 170 with the compound of EG-3896 - K20 microspheres 50\%v/v (modified PDMS). The dielectric loss became 0.0034 at $2.6 \mathrm{GHz}$, and it is comparable to commercial, rigid PCB substrates like RO4003C or RO4350B, which have dielectric loss 0.0027 and 0.0037 accordingly.

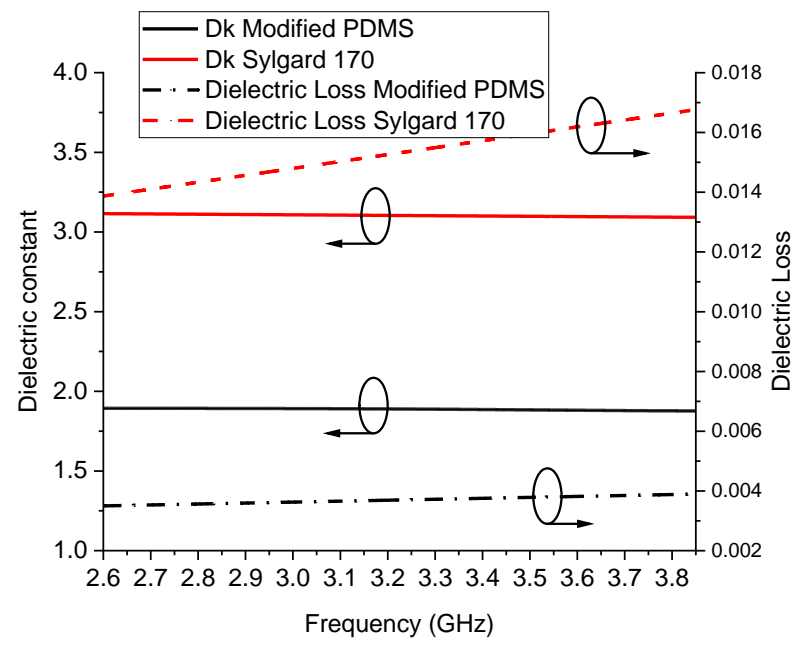

Fig. 1. Measured dielectric constants and tan loss of modified PDMS and Sylgard 170.

The further improvements have been archived with a recipe EG3896 + 50\%v/v DET $40+3 \% 7558$ co-polymer. Such combination gives no variations of dielectric constant over frequency in the wideband from $2.6 \mathrm{GHz}-12.5 \mathrm{GHz}$ and very small dielectric loss, i.e., $\mathrm{Dk}$ is equal to 1.73 and dielectric loss is $0.001 \pm 0.0005$ at $2.6 \mathrm{GHz}$ to $3.95 \mathrm{GHz}$ and $0.01-0.014$ at $8.4 \mathrm{GHz}$ to $12.5 \mathrm{GHz}$.

\section{B. Conducting Polymers}

The conducting polymers with the ability to stretch at least from $1 \%$ to $3 \%$ have been used. The polymers from EMS (CI series), and Dow Chemical (DA6534) companies have been electrically and mechanically tested at various conditions. The "uncured" state of such polymers consists of $60 \%$ silver nanoparticles in either polymer matrix with solvents in the case CI series or PDMS-based matrix in cased DA6534. TABLE I summarizes the data from the datasheet and measured conductivity. The 4-point probe technique has been used to evaluate the conductivity of the material. Some differences in conductivity, viscosity, surface roughness, stretching, and bending abilities have been detected among all polymers.

TABLE I

POLYMER CONDUCTIVITY

\begin{tabular}{ccc}
\hline \hline Name & $\begin{array}{c}\text { Datasheet Conductivity } \\
\left(10^{6} \mathrm{~S} / \mathrm{m}\right)\end{array}$ & $\begin{array}{c}\text { Measured Conductivity } \\
\left(10^{6} \mathrm{~S} / \mathrm{m}\right)\end{array}$ \\
\hline CI-1036 & 3.9 & 1.6 \\
CI-1036 mod & & 6.75 \\
CI-1075 & 3.6 & 4.2 \\
CI-4040 & 0.78 & 0.7 \\
DA6534 & 0.55 & 0.45 \\
\hline \hline
\end{tabular}

The conducting polymers can be tuned to achieve an optimum trade-off between conductivity and stretchability. The conductivity can be improved by rising metal filling in the bulk material [18] or at the interface between the substrate and conducting layer by additional passivation with metal particles [19]. We have found that the most straightforward approach (in terms of implementation and integration in our fabrication process) is to add a very small amount of conducting particles with a very large aspect ratio (length to diameter ratio) [19]. Copper nanotubes and copper nanowires would be the best solution in such a case, but it is still not available commercially. We used copper bonding wires with 50um in diameter and chopped $10-30 \mathrm{~mm}$ in length. The length has been chosen arbitrarily based on the required device's dimensions and stretchability. Such short wires could be evenly distributed either in the volume of "uncured" polymers or on the surface. The conductivity of CI-1036 has been increased four times by implementing this way (see CI-1036 mod in TABLE I).

The mechanical and temperature deepened properties of CI series are discussed in [17].

\section{Fabrication Technique}

We have developed our fabrication process based on molding technology. It allows us to employ various polymers and curing conditions. A detailed description of the production process and chemical integration among different polymers have been described in [17]. Fig. 2 illustrates the mold for the bow-tie antenna, where all parts are made from PTFE. 


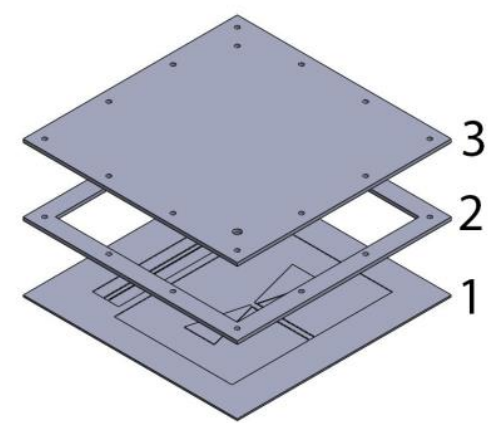

Fig. 2. The mold for the bow-tie antenna and CPW line.

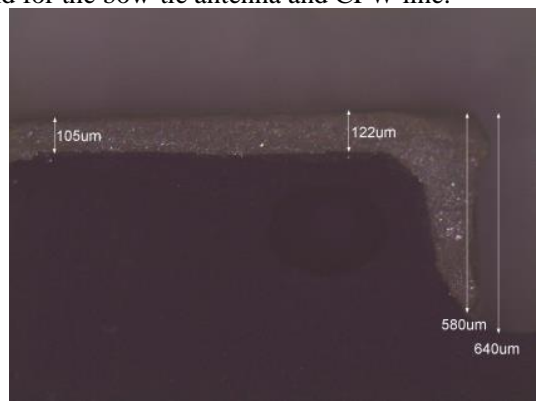

Fig. 3. The cross-section of the edge of the produced microstrip line from Sylgard 170 and conducting polymer.

The current production process has several aftermaths on the final products. One of them is a distinctive cross-section of produced conducting layers. All conducting layers have $\pi$ shapes and are illustrated in Fig. 3 and Fig. 4. This shape increases coupling effects to the nearest lines.

The substrate thickness can be varied within one design, e.g., the microstrip feeding network can have a thin layer of the dielectric to miniaturize dimensions and increase operational frequency, while the patch antennas can have a thick dielectric layer to boost antennas' bandwidth and gain. By varying the shapes and volumes in the molds for conducting and dielectric layers, we can produce and planar structures and relatively complex 3D geometries. This opens another degree of freedom to design microwave devices with unique properties.

Following the described production process, we have produced several sets of CPW fed bow-tie and microstrip fed patch antennas Fig. 4.

TABLE II

PRODUCED ANTENNAS

\begin{tabular}{lcccc}
\hline \hline & \multicolumn{2}{c}{ Bow-tie antenna } & \multicolumn{2}{c}{ Patch antenna } \\
& $\begin{array}{c}\text { Sylgard } \\
170\end{array}$ & $\begin{array}{c}\text { EG3896- } \\
\text { microspheres }\end{array}$ & $\begin{array}{c}\text { Sylgard } \\
170\end{array}$ & $\begin{array}{c}\text { EG3896- } \\
\text { microspheres }\end{array}$ \\
\hline CI-1036 & + & & + & \\
CI-1036 mod & + & + & + & + \\
CI-1075 & + & & + & + \\
CI-4040 & + & + & + & + \\
DA6534 & + & & & + \\
\hline \hline
\end{tabular}

TABLE II shows variations of materials in our investigation. Combinations of Sylgard 170 with different conducting layers will show the effect of conductivity on the antennas performance in flat and bent conditions, while combinations EG3896 with 50\% microspheres (EG3896- microspheres or modified gel) with the worse and the best conductivity will demonstrate the effect of the dielectric loss on the performance.
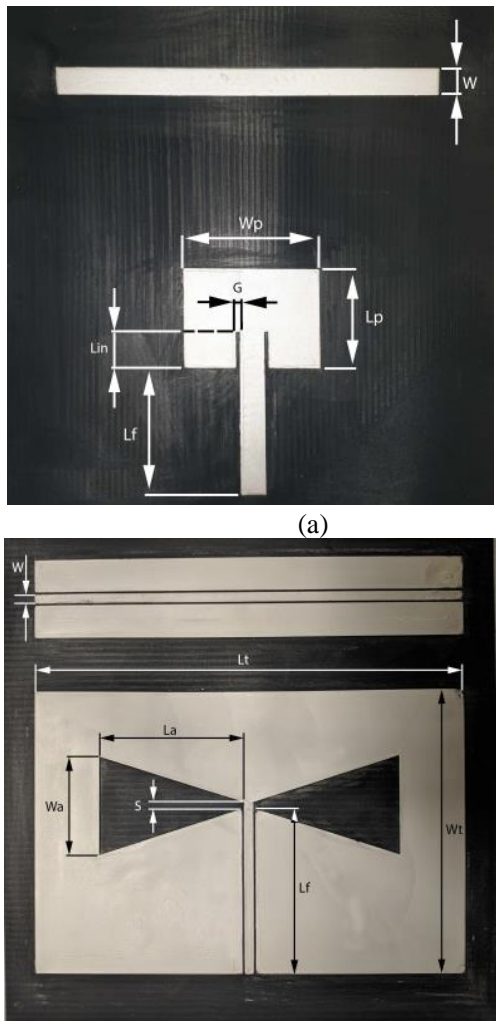

(b)

Fig. 4. Produced (a) patch antenna and microstrip line, (b) slotted bow-tie antenna, and CPW line.

TABLE III

ANTENNAS DIMENSIONS (MM)

\begin{tabular}{|c|c|c|}
\hline & Sylgard $170(\mathrm{Dk}=3.1)$ & Modified gel $(\mathrm{Dk}=1.85)$ \\
\hline \multicolumn{3}{|c|}{ Patch antenna } \\
\hline W & 8.1 & 11.5 \\
\hline G & 1.3 & 2.4 \\
\hline Lp & 32.26 & 41.2 \\
\hline Wp & 44.65 & 51.5 \\
\hline Lin & 11.5 & 12.8 \\
\hline $\mathrm{Lf}$ & 40 & 40 \\
\hline \multicolumn{3}{|c|}{ Bow-tie antenna } \\
\hline W & 2.4 & 3.9 \\
\hline CPW gap & 0.4 & 0.5 \\
\hline $\mathrm{La}$ & 45.2 & 52.64 \\
\hline $\mathrm{Wa}$ & 27.5 & 27.2 \\
\hline $\mathrm{S}$ & 1.1 & 0.5 \\
\hline $\mathrm{Lf}$ & 49.45 & 54.75 \\
\hline $\mathrm{Wt}$ & 85 & 110 \\
\hline $\mathrm{Lt}$ & 130 & 150 \\
\hline
\end{tabular}

TABLE III shows the dimensions of designed and produced antennas. The substrate thickness is $3 \mathrm{~mm}$ in all cases, which illustrates the flexibility with relatively high substrate thicknesses. Many materials that are used in the "flexible" electronics can be considered flexible only with minimal thicknesses (around 100um), e.g., polyimide (Kapton) [20], polyethylene [21], PTFE [22], and others [23], [7], [24].

CPW gaps for Dk 3.1 and 1.85 are very close due to an additional increase in the coupling by the rising height of the $\pi$-shaped "metallization" in the cross-section. The 
"metallization" thickness is around 70-100 um and exceeds five skin depths in all cases. DA6534 has 350 um in thickness since it does not have any shrinkage.

\section{Connectors}

The connectors can be soldered directly to the conducting polymers CI series and PE873 with low-temperature eutectic alloys. However, the stress between soldering can cause cracks and tears. The SMA Radiall (R125.541.000) endlaunch connectors have been modified to have a solderless connection to avoid such damage. Fig. 5 illustrates configurations for $\mathrm{CPW}$ and microstrip connection.

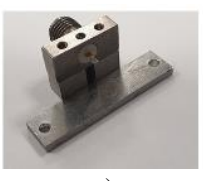

a)

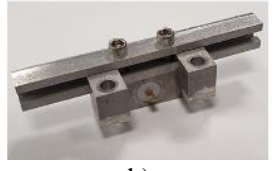

b)
Fig. 5. Modified SMA connectors for a) microstrip and b) for CPW application.

This configuration allows using connectors with very thick substrates up to $8 \mathrm{~mm}$, adjustable CPW pitch, fast connection and reconnection, and repeatable connection from one set-up to another. Since metal parts and conducting polymer have oxidation layers, the conducting silver paint has been used to enhance ohmic connection.

\section{MEASUREMENTS}

S-parameters measurements have been performed on PNA N5227A with modified SMA end-launch connectors. Special support has been designed and produced to provide rigid support for antennas in flat and bent conditions, and at the same time, it does not disturb the antenna's performance. Bending conditions have been carried out by applying antennas on the styrofoam cylinders with various diameters (200, 150, 100, and $75 \mathrm{~mm}$ are denoted by D200, D150, D100 and D75, respectively).

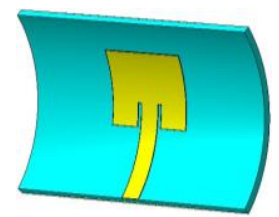

(a)

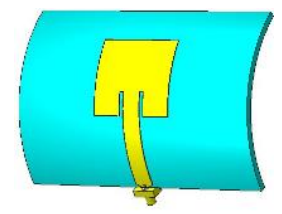

(c)

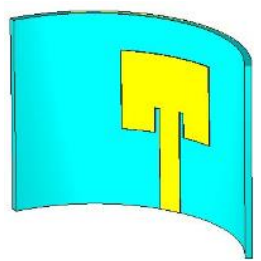

(b)

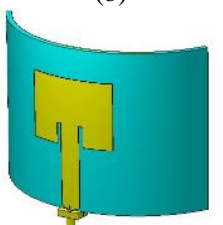

(d)
Fig. 6. Illustration of bending conditions for patch and bow-tie antennas (a) Eplane bend inside, (b) H-pane bend inside, (c) E-plane bend outside, (d) Hplane bend outside.

The radiation patterns have been measured in an anechoic chamber. It is necessary to mention that our anechoic chamber does not have an automatic system for seeking maximums in the boresight. All adjustments have been made manually, and it is possible that some of the measurements are slightly off.
The radiation patterns have been measured in the horizontal and vertical plane, including cross-polarizations. Only selected data is shown in this work.

\section{A. S-parameters Of Flat Antennas}

The patch and bow-tie antennas' reflection coefficient measurements in the flat condition are shown in Fig. 7 to Fig. 10 and compared with simulated results in CST studio (the best combination of materials). The dimensions of produced antennas have variations in 30 um or less with simulated parameters in the xy-plane and $100 \mathrm{um}$ in the z-plane. However, the $\pi$-shaped structure affects the fringing fields to the ground and the nearest metallization. For example, the frequency shift about $30 \mathrm{MHz}$ and less might be explained by the fringing field effects.

Ripples in Fig. 9 and Fig. 10 are due to the excessive amount of points in the measured data, plus the final feeding network impedance is slightly different from $50 \mathrm{ohms}$. Additionally, the insertion loss is $0.1-0.2 \mathrm{~dB}$ higher in the measured data due to modified connectors and trimmings.

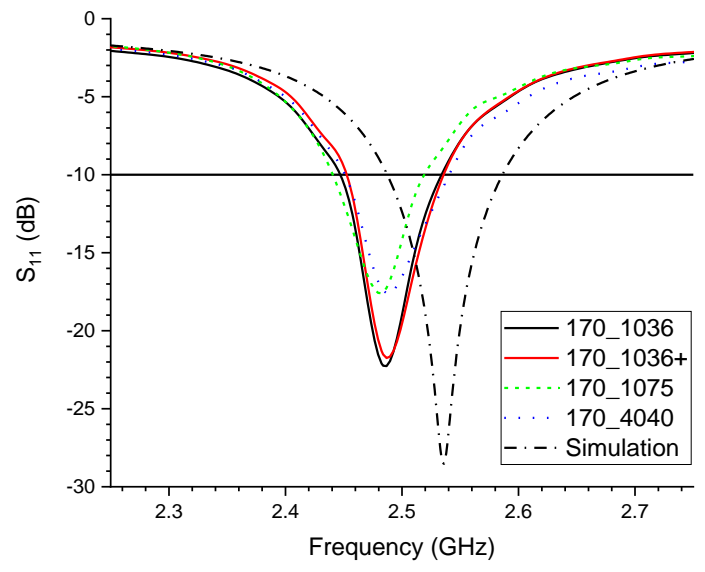

Fig. 7. Measured and simulated $S_{11}$ parameters for the patch antenna with Sylgard 170 as dielectric and various conducting polymers.

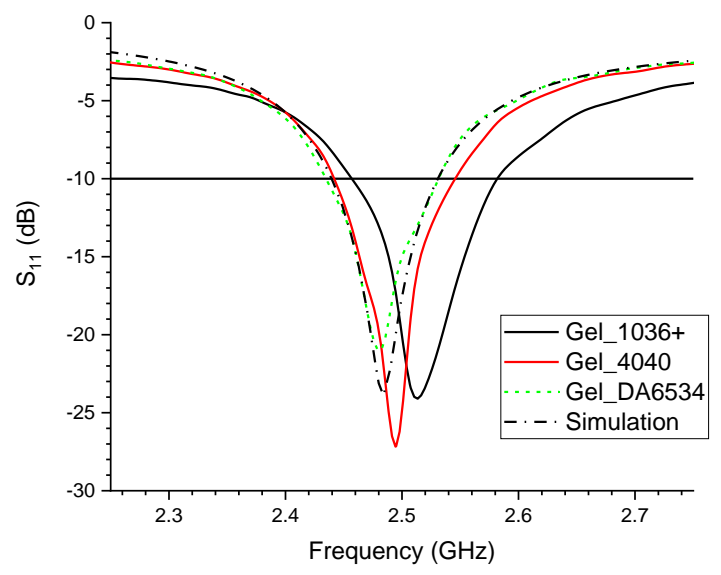

Fig. 8. Measured and simulated $S_{11}$ parameters for the patch antenna with modified EG3896 as dielectric and various conducting polymers.

Almost all reflection coefficients illustrate that less 
conductive polymers produce better matching, except DA6534. This is explained by additional ohmic losses in the conductors, which reduces reflection power from the antennas. As mentioned before, DA6534 has no shrinkage and produced patch antennas, and microstrips have a different distance between the signal and ground plane compare to other antennas. This leads to additional impedance mismatch.

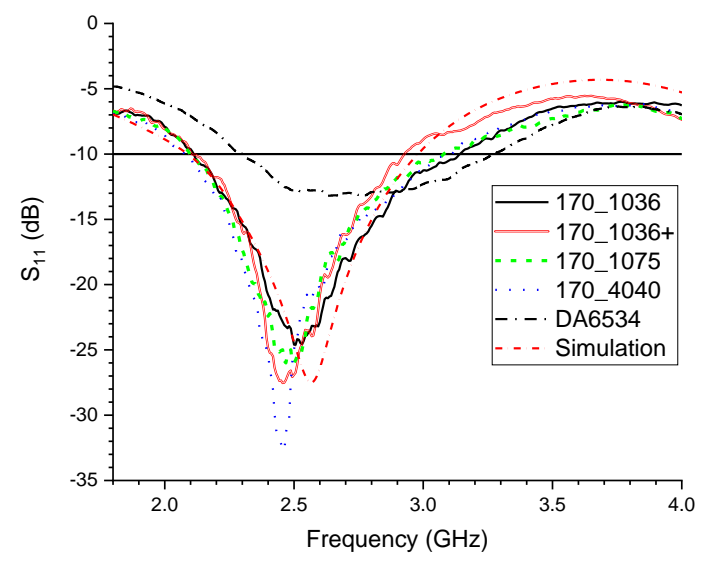

Fig. 9. Measured and simulated $S_{11}$ parameters for the bow-tie antenna with Sylgard 170 as dielectric and various conducting polymers.

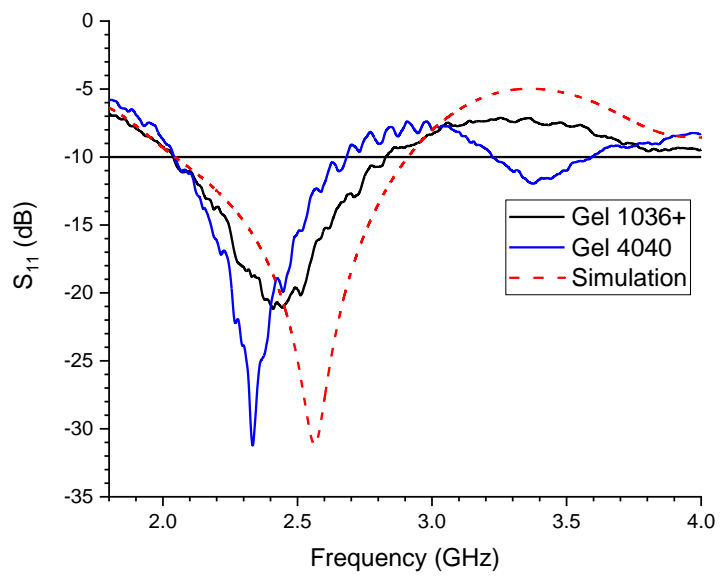

Fig. 10. Measured and simulated $S_{11}$ parameters for the bow-tie antenna with modified EG3896 as dielectric and various conducting polymers.

The expected effect of conductivity on the resonance type of antennas is in the bandwidth. Fewer losses sharpen $S_{11}$ and produce a narrower bandwidth. It is well shown in Fig. 7, i.e., CI-4040 gives $90 \mathrm{MHz}$ bandwidth, and then it gradually narrows down to $80 \mathrm{MHz}$ with modified CI-1036. However, the exact opposite effect with the low-loss dielectric in Fig. 8. Modified CI-1036 gives 124 MHz bandwidth, CI-4040 - 103 $\mathrm{MHz}$, and DA6534 - $97 \mathrm{MHz}$.

A similar picture has been observed for the bow-tie antennas. Sylgard 170 with modified CI-1036 has $815 \mathrm{MHz}$ bandwidth, CI-1075 - $975 \mathrm{MHz}, \mathrm{CI}-4040-1006 \mathrm{MHz}$, but again the exact opposite effect in with low loss dielectric in Fig. 10, i.e., modified CI- $1036-790 \mathrm{MHz}$ and CI-4040 - 645 $\mathrm{MHz}$.

\section{B. S-parameters Of Bent Antennas}

The bow-tie antenna with a combination of modified EG3896-CI-4040 and patch antenna with modified EG3896CI-1036+ have been chosen to illustrate the effect of bending on the reflection coefficient and radiation patterns. Both antennas have been bent, as shown in Fig. 6. Only selected graphs are shown for the illustration of expected and unexpected cases.

Any bending conditions induce tension and compression forces on the surface and in the bulk of the structure. These forces will deform the material based on the value of Young's modulus and Poisson's ratio. The Young's modulus of PDMS is in the range 0.1-100 MPa; $\mathrm{CI}$ conducting polymers is in the range 100-800 MPa, while the GPa range is for the Kapton and Copper. Sylgard 170 has 1.1MPa, and modified EG3896 (50\% K20 microspheres) has 140KPa Young's modulus.

Fig. 11 shows the expected frequency shift and variations in the magnitude of the patch antenna's reflection coefficients. Most deformations lead to the substrate thinning due to the unequal Young's modulus of the materials. And only small portion of the compression and stretching forces results in changes of dimensions in the conducting layers.

E-plane bend inside with the curvature diameter of $75 \mathrm{~mm}$ (D75 in Fig. 11) gives the increase in the bandwidth by $10 \mathrm{MHz}$ in the measured and $20 \mathrm{MHz}$ in the simulated results compared to the flat condition. H-plane bend inside gives the bandwidth reduction to $97 \mathrm{MHz}$ at $\mathrm{D} 200,93 \mathrm{MHz}$ at $\mathrm{D} 150$, and $51 \mathrm{MHz}$ at $\mathrm{D} 75$ in the measured data and $73 \mathrm{MHz}$ at D200, $68 \mathrm{MHz}$ at $\mathrm{D} 150,34 \mathrm{MHz}$ at $\mathrm{D} 75$ in the simulated data.

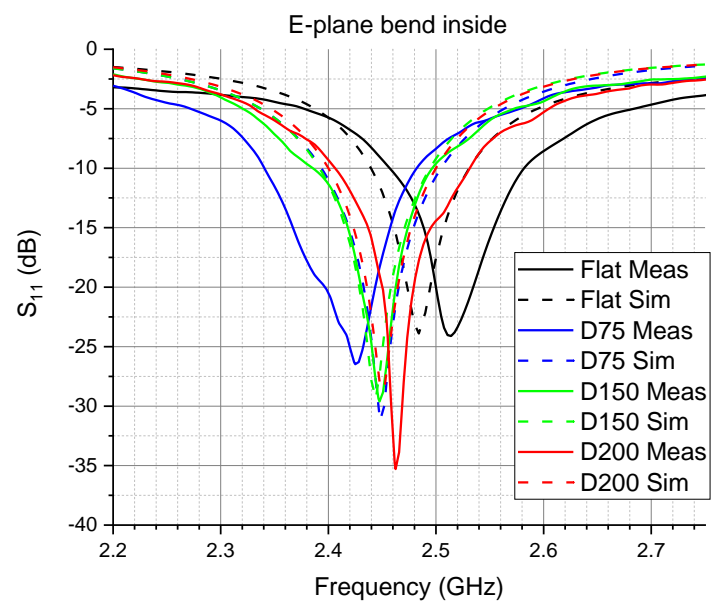

Fig. 11. Measured and simulated $S_{11}$ parameters for the bent in E-plane inside patch antenna with modified EG3896 as the dielectric.

E-plane bend outside (Fig. 12) shows the abnormal frequency shift. The simulation results indicate that the small curvature diameter leads to the lower operating frequency. Such results are well understood if the signal plane would stretch enough. However, the stiffer conducting plane enforces rather a compression of the substrate than stretching in the signal plane. CST simulations with correct values of Young's modulus and Poisson's coefficients can not accurately predict 
physical deformations. Nevertheless, both types of deformations result in the impedance mismatch versus curvature diameter. E-plane bend outside with the curvature diameter $75 \mathrm{~mm}$ gives $25 \mathrm{MHz}$ reduction in the bandwidth in the measured and $34 \mathrm{MHz}$ in the simulated results compare to the flat condition. H-plane bends outside gives an increase in the bandwidth to $143 \mathrm{MHz}$ at D200, $130 \mathrm{MHz}$ at D150, and $160 \mathrm{MHz}$ at D75 in the measured data and $97 \mathrm{MHz}$ at D200, $98 \mathrm{MHz}$ at D150, $99 \mathrm{MHz}$ at D75 in the simulated data.

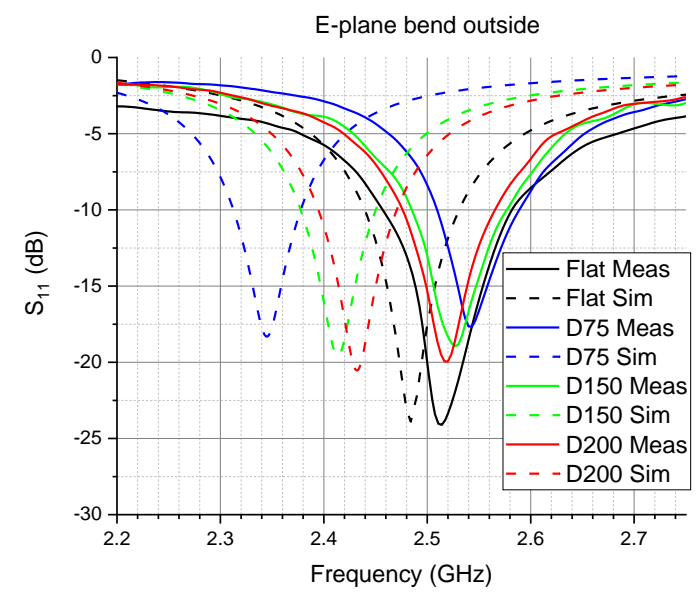

Fig. 12. Measured and simulated $S_{11}$ parameters for the bent in E-plane outside patch antenna with modified EG3896 as the dielectric.

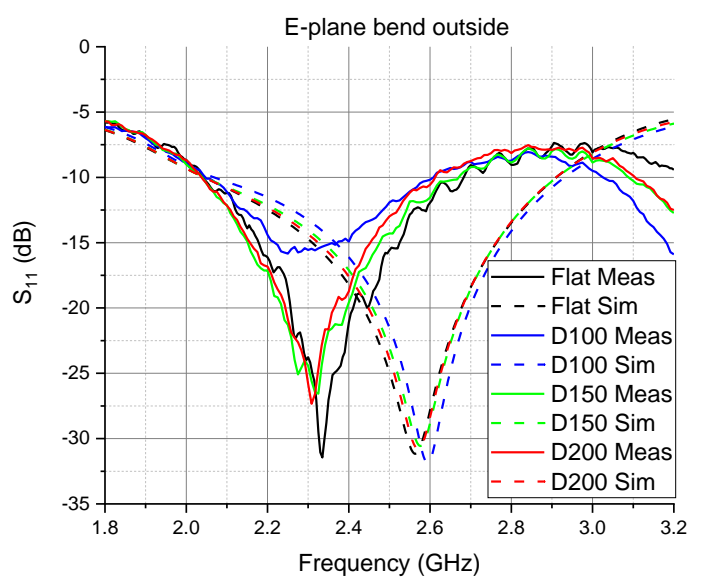

Fig. 13. Measured and simulated $S_{11}$ parameters for the bent in E-plane outside bow-tie antenna with modified EG3896 as the dielectric.

The bow-tie antenna has only one layer of dielectric and conductor. Bending inside or outside will have similar results to the patch antennas in the impedance mismatch. The bidirectional, symmetrical radiation pattern can provide information about both types of bending with one measurement. Fig. 13 illustrates the similar effects with the patch antenna, i.e., the impedance matching is getting worse by reducing curvature diameter in measured data. The operational frequency shifts left with a simultaneous reduction in the bandwidth by $87 \mathrm{MHz}$ with D100 compare to the flat condition of measured and simulated data. Although, the Eplane bend outside simulation data shows a slight increase in the operational frequency.
The H-plane bend outside (Fig. 14) indicates some improvements in the impedance match. The bandwidth slightly improves from $645 \mathrm{MHz}$ in the flat condition to 706 $\mathrm{MHz}$ at D200 and then reduces to $560 \mathrm{MHz}$ at D150 and 459 $\mathrm{MHz}$ at D100 in the measured data. Simulation results show $947 \mathrm{MHz}$ bandwidth in the flat condition, $844 \mathrm{MHz}$ at D200, $836 \mathrm{MHz}$ at $\mathrm{D} 150,790 \mathrm{MHz}$ at $\mathrm{D} 100$. The maximum bandwidth shift is $186 \mathrm{MHz}$ and $157 \mathrm{MHz}$ in the measured and simulated data, respectively.

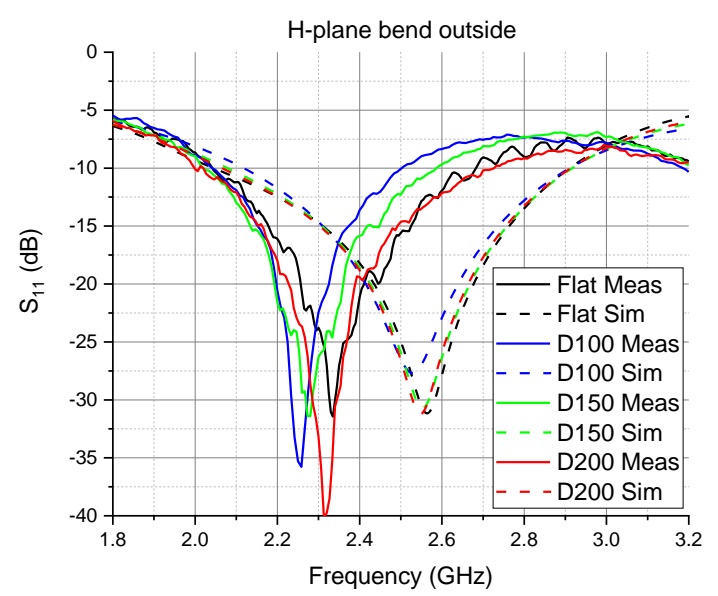

Fig. 14. Measured and simulated $S_{11}$ parameters for the bent in H-plane outside bow-tie antenna with modified EG3896 as the dielectric.

\section{Antennas Radiation Patterns in Flat Condition}

The maximum realized antenna gain and radiation pattern have been measured in horizontal and vertical planes for the patch and bow-tie antennas. Fig. 15 and Fig. 16 illustrate the maximum realized gain of the patch antenna. The simulation results are lower than the measured one by $0.8-0.5 \mathrm{dBi}$. However, there are no such discrepancies in the bow-tie results. The dimensional variations and connectors' effects have been considered, and the only reasonable explanation could be that the additional fringing fields ( $\pi$-shaped edges) can have an enhanced effect in the resonance antenna types.

The patch antennas' maximum realized gains are $7.76 \mathrm{dBi}$ and $9.16 \mathrm{dBi}$ with Sylgard 170 and modified EG3896, respectively. The conductivity variations give $0.3-0.5 \mathrm{dBi}$ degradation when the conductivity is above $10^{6} \mathrm{~S} / \mathrm{m}$. While the reduction of conductivity below $10^{6} \mathrm{~S} / \mathrm{m}$ can significantly reduce the realized gain, as shown in Fig. 18 for the bow-tie antenna. 


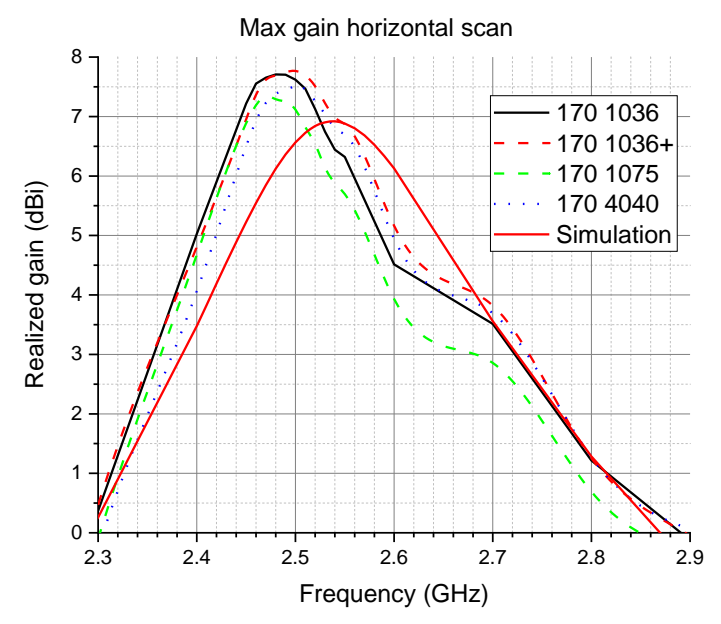

Fig. 15. Maximum realized gain vs. frequency for the patch antenna with Sylgard 170 as dielectric and various conducting polymers.

The patch antennas with Sylgard 170 have the $3 \mathrm{~dB}$ bandwidth in horizontal and vertical planes around 74 degrees in measured and 78 degrees in simulated data with no effects from conductivity. Although, modified EG3896 has some variations from $60 \mathrm{deg}$ with CI-1036+ to $68 \mathrm{deg}$ with CI-4040 in the horizontal plane. While the vertical plane scan shows 79 deg with CI-1036+ and $70 \mathrm{deg}$ with CI-4040. The level of cross-polarization varies from $-35 \mathrm{dBi}$ to $-17 \mathrm{dBi}$ with the conductivity and dielectric loss. The measured data shows that the level of cross-polarization is directly proportional to losses. This level stays below $-20 \mathrm{~dB}$ for all cases.

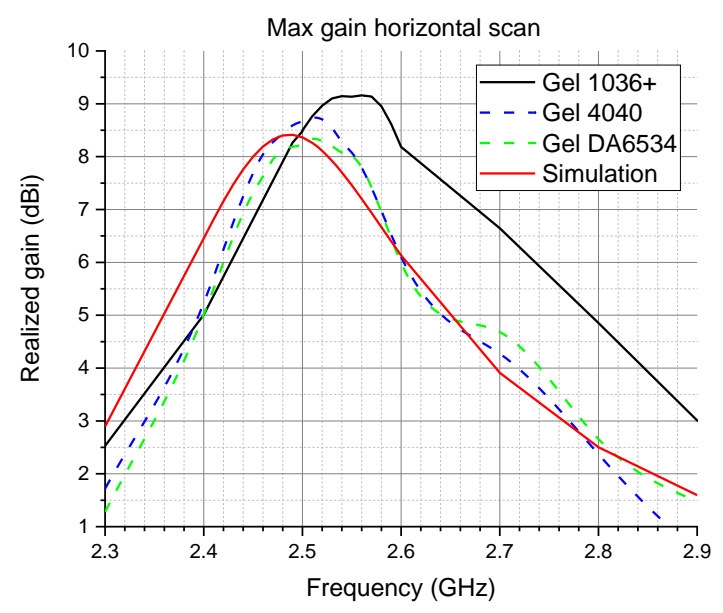

Fig. 16. Maximum realized gain vs. frequency for the patch antenna with modified EG3896 as dielectric and various conducting polymers.

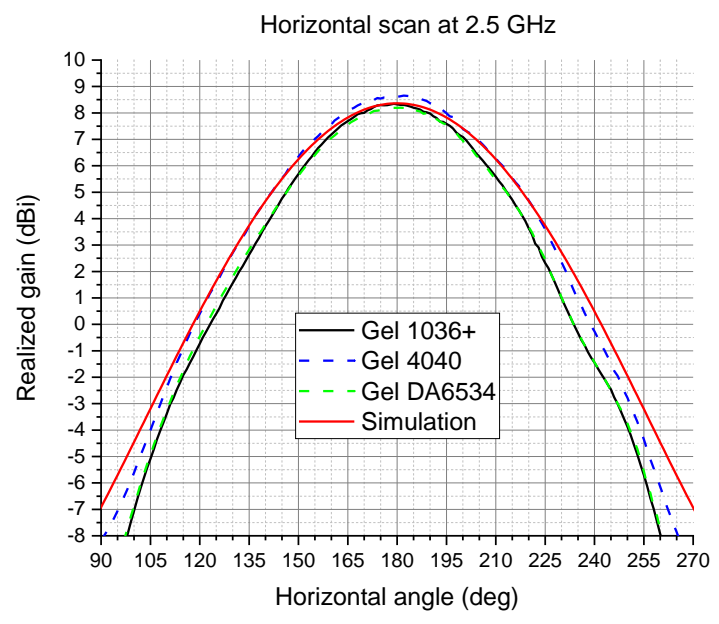

Fig. 17. Maximum realized gain vs. angle for the patch antenna with modified EG3896 as dielectric and various conducting polymers at $2.5 \mathrm{GHz}$.

The maximum realized gains for the bow-tie antennas are 7.1dBi and 7.9dBi with Sylgard 170 and modified EG3896, respectively. Fig. 20 shows the spike at $3.1 \mathrm{GHz}$; this is cumulative radiation from the antenna and the feeding network. The feeding network has $50 \mathrm{~mm}$ length, which is exactly half-wavelength at $3.1 \mathrm{GHz}$.

The bow-tie antennas with Sylgard 170 have the $3 \mathrm{~dB}$ bandwidth in the vertical plane around 74 degrees and 56 degrees in the horizontal plane with no variations from conductivity. However, modified EG3896 shows a similar behavior as with the patch antennas case. CI-1036+ has $72 \mathrm{deg}$ in the vertical plane and $49 \mathrm{deg}$ in the horizontal plane, while CI-4040 shows $60 \mathrm{deg}$ and $55 \mathrm{deg}$ in the vertical and horizontal plane. The level of cross-polarization stays below $16 \mathrm{~dB}$ for Sylgard and $-25 \mathrm{~dB}$ for modified EG3896 and degrades with a reduction of conductivity.

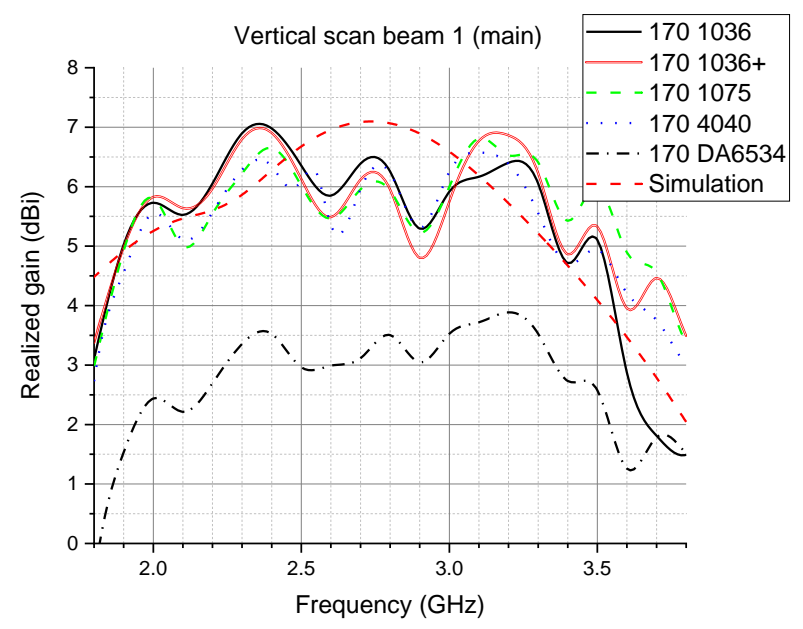

Fig. 18. Maximum realized gain vs. frequency for the bow-tie antenna with Sylgard 170 as dielectric and various conducting polymers. 


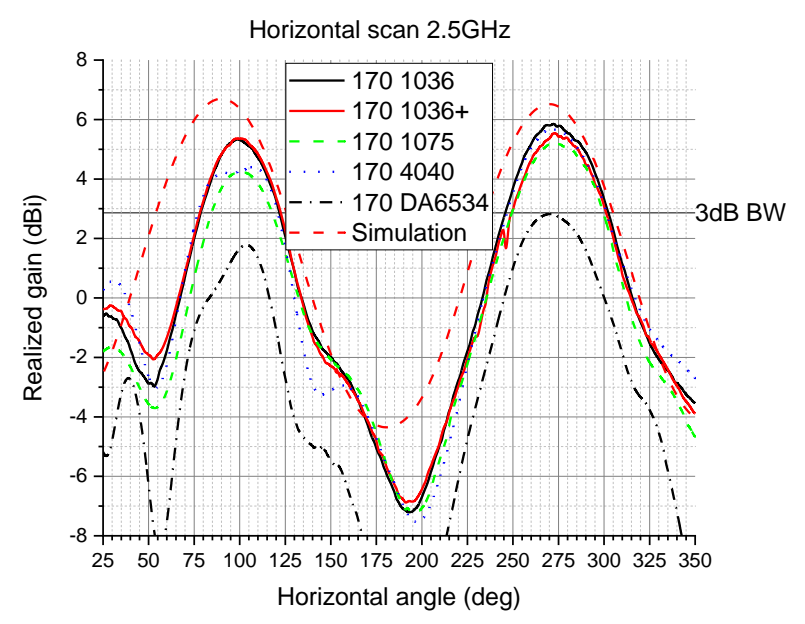

Fig. 19. Maximum realized gain vs. angle for the bow-tie antenna with Sylgard 170 as dielectric and various conducting polymers at $2.5 \mathrm{GHz} .275$ deg is the main lobe direction.

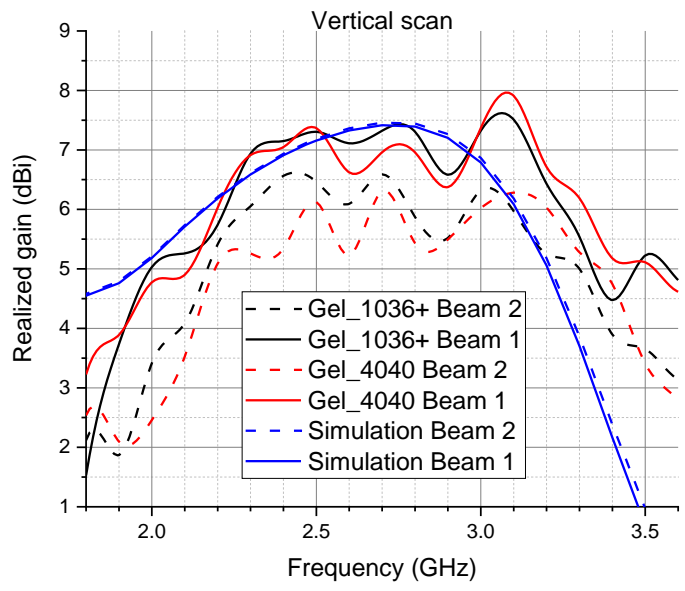

Fig. 20. Maximum realized gain vs. frequency for the bow-tie antenna with modified EG3896 as dielectric and various conducting polymers.

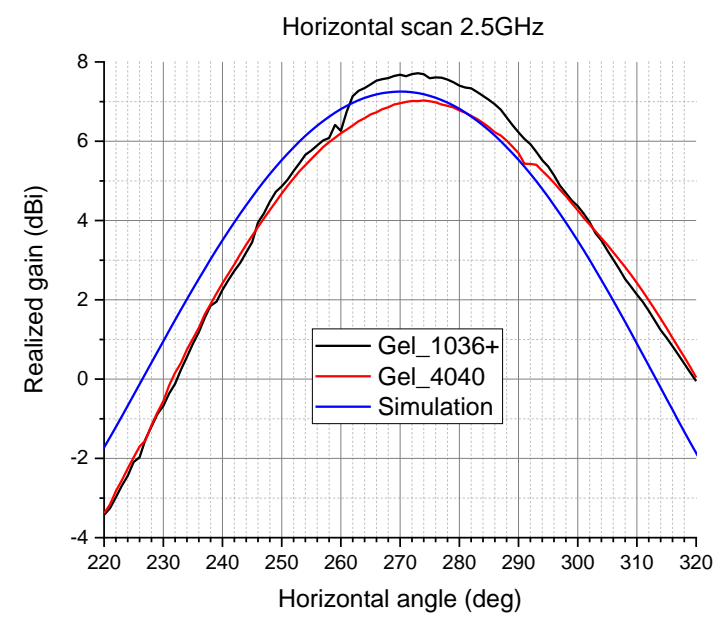

Fig. 21. Maximum realized gain vs. angle for the bow-tie antenna with modified EG3896 as dielectric and various conducting polymers at $2.5 \mathrm{GHz}$.

\section{Antennas Radiation Patterns in Bent Condition}

The effect of bending on the radiation patterns have been investigated for both types of antennas. The E-pane bend inside in Fig. 22 and Fig. 25 exhibit significant improvements in the realized gain, while other types of deformations show only reductions in the gain. Fig. 11 indicates that the reflection coefficient shifts left with bending with minor improvements in matching conditions, which is no enough to explain rising in the gain from $8.6 \mathrm{dBi}$ to $10.1 \mathrm{dBi}$ in Fig. 22 for patch antenna. The bow-tie antenna in Fig. 25 shows improvements from $7.34 \mathrm{dBi}$ to $8.38 \mathrm{dBi}$ at $2.5 \mathrm{GHz}$ and at the maximum peaks from $7.9 \mathrm{dBi}$ to $11.3 \mathrm{dBi}$. Puzzlingly, CST simulation results fail to predict any gain effects for the patch antenna and show some improvements for the bow-tie. Although the simulation results are generally very close to measured, there are discrepancies at $3.1 \mathrm{GHz}$ due to additional contribution from the feeding network radiation, and it has not been reflected in the simulation results. As shown in Fig. 15 and Fig. 16 for the patch antenna, simulation results are underestimated for the antenna gain due to probable excessive fringing fields.

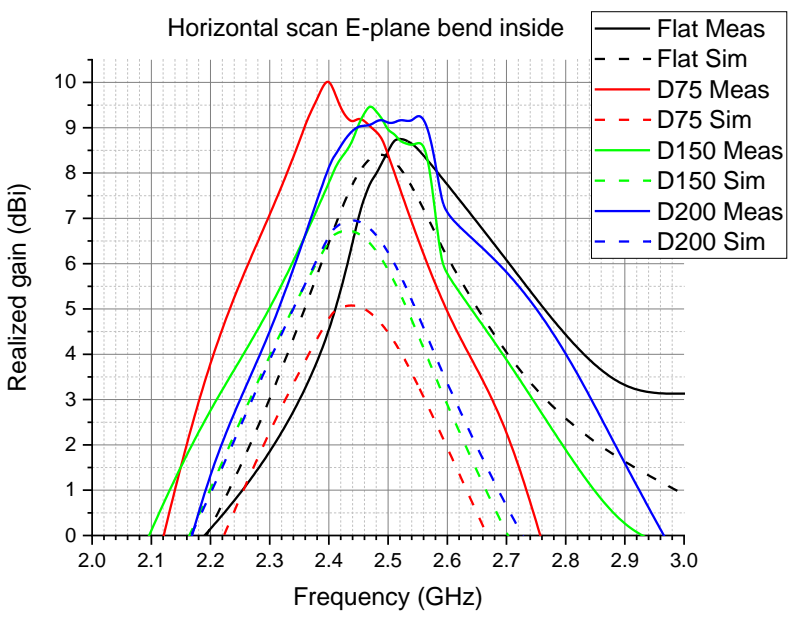

Fig. 22. Measured and simulated realized gain vs. frequency for the bent in Eplane inside patch antenna with modified EG3896.

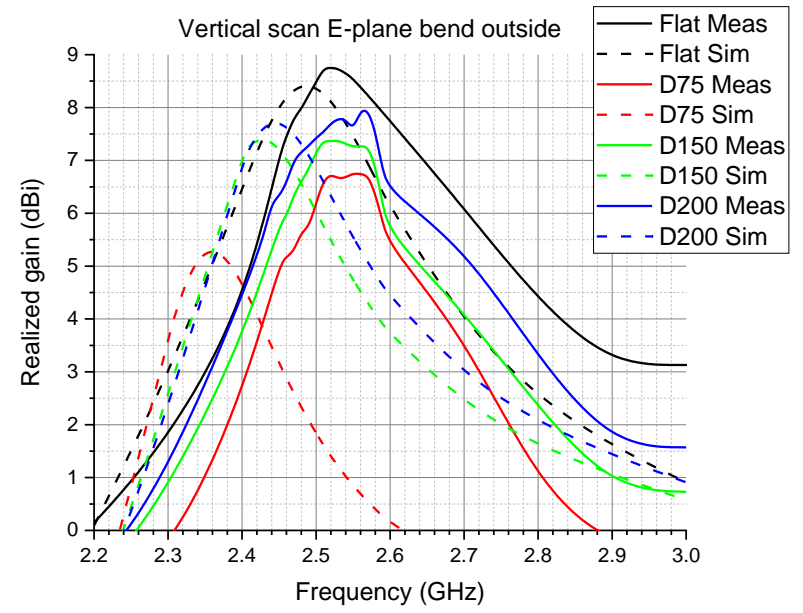

Fig. 23. Measured and simulated realized gain vs. frequency for the bent in Eplane outside patch antenna with modified EG3896. 


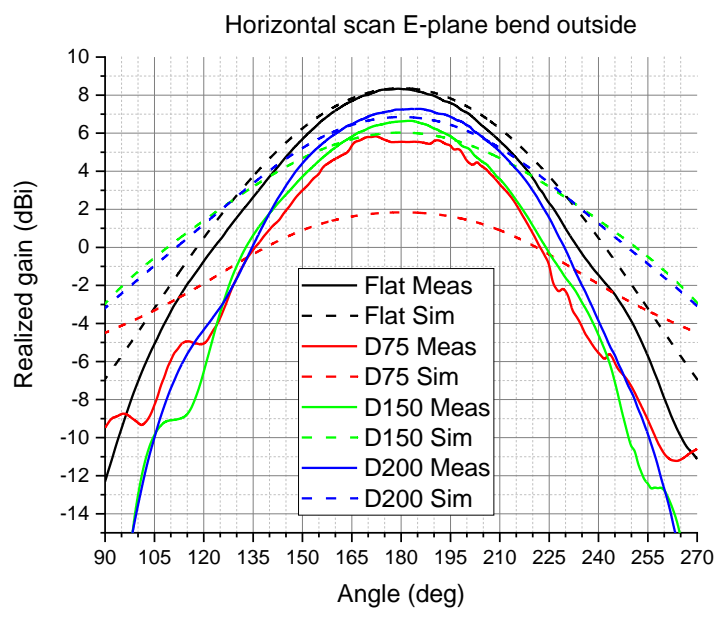

Fig. 24. Measured and simulated realized gain vs. angle for the bent in Eplane outside patch antenna with modified EG3896 at $2.5 \mathrm{GHz}$.

It seems that the general trend of the gain improvements with E-plane bend inside might come from a focusing effect. The $3 \mathrm{~dB}$ bandwidth of the beam in Fig. 22 changes with the curvature in the vertical plane, i.e., 79 degrees is in the flat condition, 66 degrees with D200, 59 degrees with D150, and 49 degrees with $\mathrm{D} 75$. The $3 \mathrm{~dB}$ bandwidth in the horizontal plane remains around 60 degrees with all curvatures in measured data at $2.5 \mathrm{GHz}$ for the patch antenna.

The bow-tie antenna does not exhibit such big changes at $2.5 \mathrm{GHz}$. Even though there is $1.3 \mathrm{dBi}$ improvement with D200 curvature, the $3 \mathrm{~dB}$ bandwidth narrows down just by 5 degrees in the horizontal and 2 degrees in the vertical plane. The further bending has a negative effect, and the $3 \mathrm{~dB}$ bandwidth widens. However, the nulls become closer proportionally to the curvature. The most drastic effect is being seen at 3.1-3.2 $\mathrm{GHz}$. The $3 \mathrm{~dB}$ bandwidth reduces from 92 degrees in the flat to 47 degrees at D100 with a similar reduction of the angle between nulls.

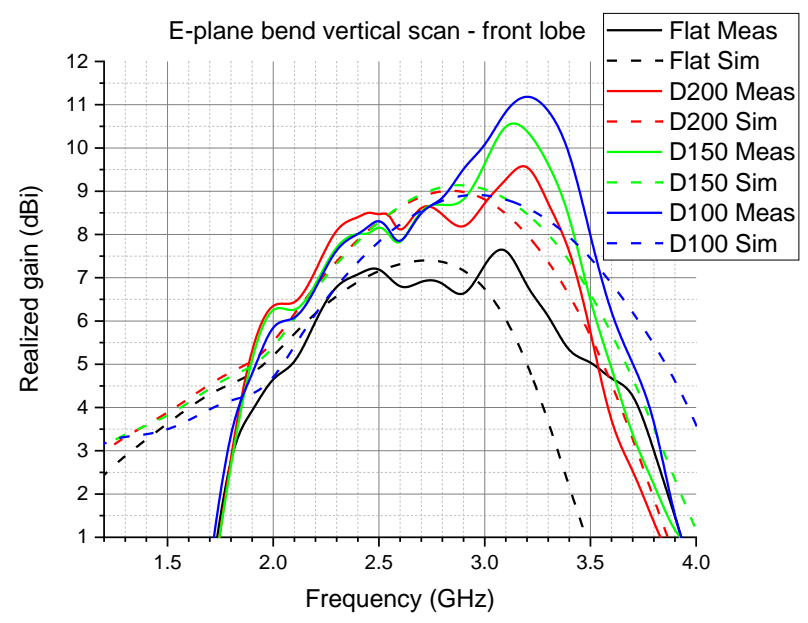

Fig. 25. Measured and simulated realized gain vs. frequency for the bent in Eplane inside bow-tie antenna with modified EG3896.

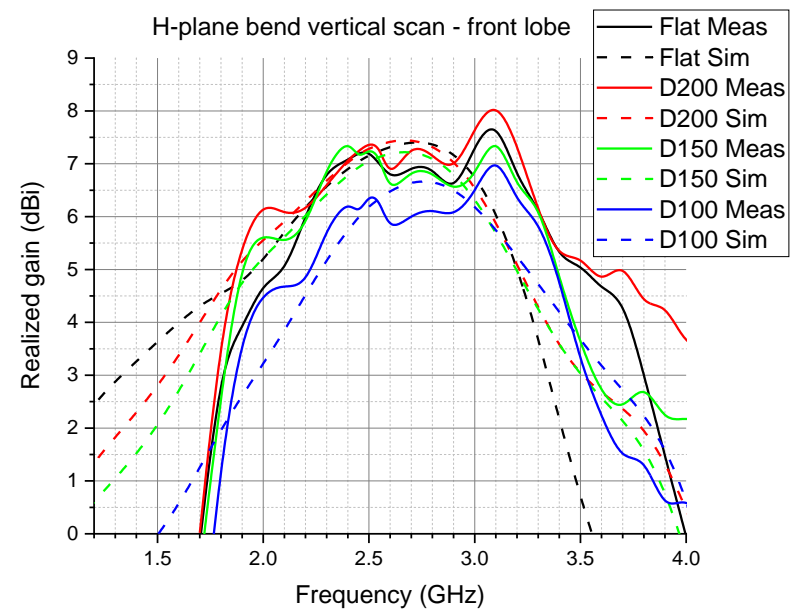

Fig. 26. Measured and simulated realized gain vs. frequency for the bent in $\mathrm{H}-$ plane inside bow-tie antenna with modified EG3896.

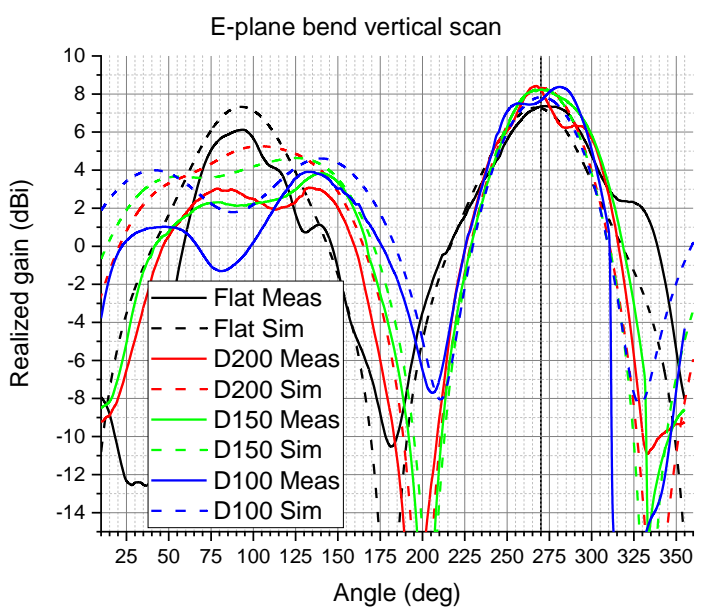

Fig. 27. Measured and simulated realized gain vs. angle for the bent in Eplane inside bow-tie antenna with modified EG3896 at $2.5 \mathrm{GHz}$.

The back lobe of the bow-tie antenna exhibits bending outside (Fig. 27) and illustrates that the beam is splitting at certain curvatures. This can be explained that the elements of the antenna become orthogonal, and the produced EM fields no longer complement each other. We can also observe that the $3 \mathrm{~dB}$ bandwidth is rapidly increasing, the realized gain is decreasing, and the angle between nulls is rising.

The H-plane and E-plane bend outside for the investigated antennas cause only degradations. Although, certain curvatures in H-plane with bending inside can have slight improvement effects as for the patch and for the bow-tie antennas. The patch antenna gains an additional $0.5 \mathrm{~dB}$ at the D200 and then reduced by $3 \mathrm{~dB}$ at D75, without any frequency shifts. The bow-tie antenna gains up to $1 \mathrm{~dB}$ at D200, then up to $0.6 \mathrm{~dB}$ at $\mathrm{D} 150$, and then the realized gain drops by $1 \mathrm{~dB}$ at D100 (compare to the flat condition).

It is necessary to mention that all antennas have been aligned to the maximum gain at $2.5 \mathrm{GHz}$, but the main lobe direction is drifting with frequency. For the same reason, the measured gains and bandwidth might not be exactly as they are, but reasonably close. 


\section{E. Summary of Material Effect on Antenna Performance}

It is undeniable that any loss has a negative effect, and it is desirable to have as better conductivity and lower dielectric loss as possible. Unfortunately, we must sacrifice one or another parameter in order to achieve flexibility. Fig. 28 and Fig. 29 illustrate the measured and simulated data of conductivity and dielectric loss effects for the bow-tie and patch antennas. The data is fair for these types of antennas and might be different for others. The two dots are out of the trends in Fig. 28. They belong to CI-1075 polymer $\left(\approx 4 \times 10^{6}\right.$ $\mathrm{S} / \mathrm{m})$. This particular polymer in our batch has some problems in consistency, and measured conductivity varies from sample to sample. These two dots might be excluded from further discussion.

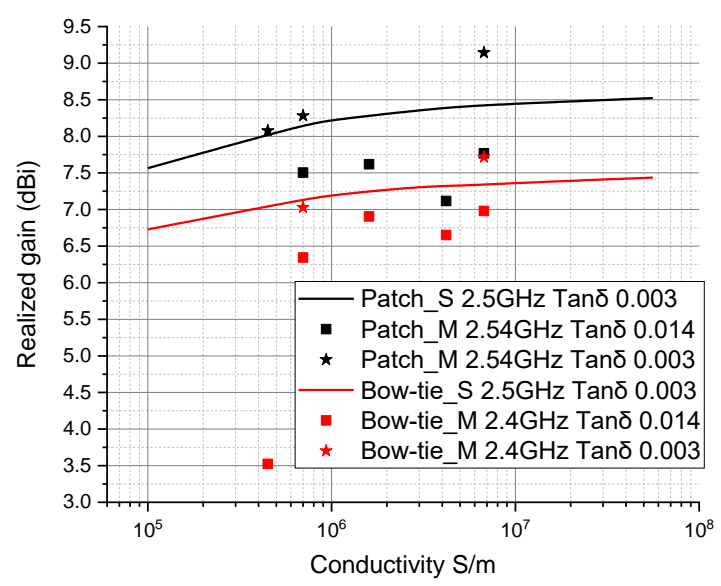

Fig. 28. Measured and simulated relations between the realized antennas gain and conductivity at $2.5 \mathrm{GHz}$. S denotes simulated data, $\mathrm{M}$ - measured data.

The dielectric loss has a more significant effect on the patch antenna rather than on the bow-tie. The slope of the curves in Fig. 29 indicates that dielectric loss below 0.01 is not desirable for patch antenna, and other types of antennas can be considered for better performance, e.g., the bow-tie or might be even simple dipoles if there is no choice in the dielectric materials. The dielectric loss can be greatly reduced by proper material selection and compounding. Although, there is a plateau where further dielectric loss reduction does not give significant benefits for the antenna gain at a certain operational frequency. The measured data follows the simulated trends but has some discrepancies due to various reasons, e.g., variations in the surface roughness, consistency, measured errors, fiending fields, etc.

The ohmic loss has similar trends as for the dielectric loss, and it can be noticed that the slope increases at the conductivities below $10^{6} \mathrm{~S} / \mathrm{m}$. However, the measured trends indicate that the bow-tie antennas are more sensitive for low conductivity, and the measured slope is way greater than for the patch antennas. The further improvements of the conducting polymers are rather challenging, and inevitably reduces the ability to stretch, and can benefit only for a small margin. Although, it is fair for the antennas themselves with a relatively simple feeding network, and it must be reconsidered for the complex feeding networks as in antenna arrays. The experimental results show that the conductivity around $10^{6}$ $\mathrm{S} / \mathrm{m}$ might be an optimum value. It allows us to tune and find an optimum trade-off between mechanical and electrical properties with minimum effort. The further material improvements might be directed towards the reduction in the dielectric losses. It will allow us to raise the operational frequencies for the flexible polymer-based microwave electronics.

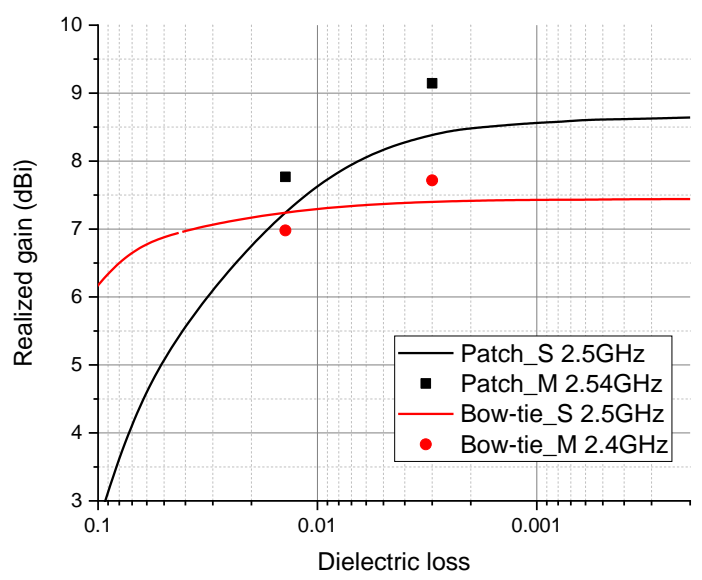

Fig. 29. Measured and simulated relations between the realized antennas gain and dielectric loss at $2.5 \mathrm{GHz}$. S denotes simulated data, $\mathrm{M}$ - measured data.

\section{F. Comparison with Other Flexible Antennas}

TABLE IV summarizes antennas' performance of flexible antennas. Some antennas exhibit semi-rigid properties due to very thin structures, even though they have been produced from rigid substrates, e.g., RO4003 or Duroid 5880. The same can be extended to the Kapton (polyimide), PET, PEN, LCP, Teflon (PTFE), and other plastic substrates. These plastics do not exhibit elastomer's properties and can be used for flexible microwave electronics within certain thickness constraints. The usage of metals and rigid inks for the conducting materials has its own limits too, due to their extremely small elongations ( $1 \%$ or less).

Several patch antennas have been produced with PE873 polymer (TABLE IV) but do not exhibit good performance $(0.9 \mathrm{~dB},-7.2 \mathrm{~dB})$. This happens due to the paintbrush production process. The pain brush technique does not give acceptable precision in the xy-plane and has no control on the final layer thicknesses. The produced layers can have variations from few microns to several dozens of microns, which will create a random pattern with high resistant areas, areas with excessive radiations, and increase the surface roughness. Additionally, the polymer integration must be done to avoid layer separations and misplacements of the conducting layers. Apparently, the surface roughness has had a great effect on the performance of bow-tie antenna with the leather substrate, even with relatively high conductivity of silver ink around $8-9 \times 10^{5} \mathrm{~S} / \mathrm{m}$ and dielectric loss around 0.07 . The moderate performance of antennas on the classical Roger and Duroid substrates with copper cladding might be due to design specifics or imperfections. 
TABLE IV

PERFORMANCE OF FLEXIBLE ANTENNAS IN THE FLAT CONDITION

\begin{tabular}{|c|c|c|c|c|}
\hline $\begin{array}{l}\text { Antenna } \\
\text { type, ref }\end{array}$ & $\begin{array}{l}\text { Dielectric, } \\
\text { thickness }\end{array}$ & $\begin{array}{c}\text { Conductor, } \\
\text { thickness }\end{array}$ & $\begin{array}{l}\text { Operational } \\
\text { frequency } \\
(\mathrm{GHz})\end{array}$ & $\begin{array}{l}\text { Antenna } \\
\text { gain }\end{array}$ \\
\hline $\begin{array}{l}\text { Patch, } \\
\text { this work }\end{array}$ & $\begin{array}{l}\text { Mod PDMS, } \\
3 \mathrm{~mm}\end{array}$ & $\begin{array}{l}\text { Polymer, } \\
\text { 70-100um }\end{array}$ & $2.45-2.58$ & $7-9.16 \mathrm{dBi}$ \\
\hline $\begin{array}{l}\text { Patch, } \\
{[25]}\end{array}$ & $\begin{array}{c}\text { PDMS } \\
\text { (Sylgard 184), } \\
3.18 \mathrm{~mm}\end{array}$ & $\begin{array}{c}\text { Fabric } \\
\text { NCS95R- } \\
\text { CR, 130um }\end{array}$ & $2.28-2.32$ & $\begin{array}{c}2.9-3.3 \\
\mathrm{dBi}\end{array}$ \\
\hline $\begin{array}{l}\text { Patch, } \\
{[26]}\end{array}$ & $\begin{array}{l}\text { Unknown } \\
\text { rubber, } 1.4 \mathrm{~mm}\end{array}$ & $\begin{array}{l}\text { Polymer } \\
\text { PE873, } \\
\text { 30um }\end{array}$ & $2.35-2.45$ & $0.9 \mathrm{~dB}$ \\
\hline $\begin{array}{l}\text { Patch, } \\
\text { [27] }\end{array}$ & $\begin{array}{l}\text { NinjaFlex, } \\
1.2 \mathrm{~mm}\end{array}$ & $\begin{array}{l}\text { Polymer } \\
\text { PE873, } \\
\text { 30um }\end{array}$ & $1.94-2.93$ & $-7.2 \mathrm{~dB}$ \\
\hline $\begin{array}{l}\text { Patch, } \\
{[28]}\end{array}$ & $\begin{array}{l}\text { PDMS, } \\
1.6 \mathrm{~mm}\end{array}$ & $\begin{array}{l}\text { VeilShield } \\
\text { mesh, } \\
\text { 57um }\end{array}$ & $2.35-2.55$ & $1.8 \mathrm{dBi}$ \\
\hline $\begin{array}{l}\text { Bow-tie, } \\
\text { this work }\end{array}$ & $\begin{array}{l}\text { Mod PDMS, } \\
3 \mathrm{~mm}\end{array}$ & $\begin{array}{l}\text { Polymer, } \\
\text { 70-100um }\end{array}$ & $2-2.8$ & $5-7.9 \mathrm{dBi}$ \\
\hline $\begin{array}{c}\text { Bow-tie, } \\
{[21]}\end{array}$ & PET, 135um & $\begin{array}{l}\text { Silver ink, } \\
\text { 3.7um }\end{array}$ & $2.1-4.35$ & $\begin{array}{c}\text { 4-6.3 dB } \\
\text { Simulation }\end{array}$ \\
\hline $\begin{array}{c}\text { Bow-tie, } \\
\text { [29] }\end{array}$ & $\begin{array}{c}\text { Duroid 5880, } \\
\text { 787um }\end{array}$ & $\begin{array}{l}\text { Copper, } \\
\text { 35um }\end{array}$ & $0.81-1.87$ & $\begin{array}{c}3.8-4.78 \\
\mathrm{dBi}\end{array}$ \\
\hline $\begin{array}{c}\text { Bow-tie, } \\
{[30]}\end{array}$ & $\begin{array}{l}\text { RO4003C, } \\
\text { 200um }\end{array}$ & $\begin{array}{l}\text { Copper, } \\
\text { 35um }\end{array}$ & $2.2-4$ & $\begin{array}{c}2.2-6.3 \\
\mathrm{dBi}\end{array}$ \\
\hline $\begin{array}{c}\text { Bow-tie, } \\
{[31]}\end{array}$ & $\begin{array}{l}\text { Leather, } \\
\text { 900um }\end{array}$ & $\begin{array}{l}\text { Ag-ink, } \\
\text { unknown }\end{array}$ & $1.48-1.7$ & $-2.5 \mathrm{dBi}$ \\
\hline
\end{tabular}

\section{CONCLUSION}

In this paper, we have demonstrated that proper material selection, material engineering, and production process of polymer-based flexible microwave electronics can achieve competitive performance compared to rigid PCB technology. Classical designs of the patch and bow-tie antennas have been realized with various polymers to investigate the effects of the dielectric loss and conductivity on the antennas' performance in the S-band in order to find acceptable limits for further flexibility improvements.

The proposed recipes for low-loss, low-Dk dielectric materials and chemical integration between conducting polymers and PDMS have been presented and tried on several microwave devices. The current molding process allows us to step out from 2D PCB designs and build 3D structures or hybrid PCB-3D components with a certain freedom in material properties. Additionally, the new material exhibits unique mechanical properties, i.e., low density, thermal insulation, vibration and acoustic-damping effects, low humidity absorption, etc., which extends the material application to other fields.

The antenna's structures have non-classical features like $\pi$ shaped edges, which lead to additional fringing fields. We have found that the fringing fields affect the resonance type of antennas like the patch antenna. It is possible to have enhanced antenna gain by the intentional shaping of conductors in certain ways. However, it is still a subject for further investigation.

The bending effects have been investigated too, and it has been demonstrated that the E-plane bend inside has the focusing effect and boosts the antenna gain. This can be exploited by producing pre-shaped structures of classical antennas either by current production or 3D printing, which might benefit not only single antenna elements but also arrays.

\section{ACKNOWLEDGMENT}

The authors gratefully acknowledge support from Dow Corning chemical department of Singapore and 3M, Nouryon companies for provided samples.

\section{REFERENCES}

[1] A. Afyf, A. Elouerghi, M. Afyf, M. A. Sennouni, and L. Bellarbi, "Flexible Wearable Antenna for Body Centric Wireless Communication in S-Band," 2020 Int. Conf. Electr. Inf. Technol. ICEIT 2020, pp. 5-8, 2020.

[2] Y. H. Jung et al., "A Compact Parylene-Coated WLAN Flexible Antenna for Implantable Electronics," IEEE Antennas Wirel. Propag. Lett., vol. 15, no. 560 m, pp. 1382-1385, 2016.

[3] A. Veeraselvam, G. N. A. Mohammed, K. Savarimuthu, M. Marimuthu, and B. Balasubramanian, "Polarization diversity enabled flexible directional UWB monopole antenna for WBAN communications," Int. J. RF Microw. Comput. Eng., vol. 30, no. 9, pp. 1-12, 2020.

[4] H. Lee, M. M. Tentzeris, and J. Geiger, "Flexible spiral antenna with microstrip tapered infinite balun for wearable applications," IEEE Antennas Propag. Soc. AP-S Int. Symp., pp. 1-2, 2012.

[5] Q. H. Abbasi, M. U. Rehman, X. Yang, A. Alomainy, K. Qaraqe, and E. Serpedin, "Ultrawideband band-notched flexible antenna for wearable applications," IEEE Antennas Wirel. Propag. Lett., vol. 12, pp. 1606$1609,2013$.

[6] F. Tariq, Q. Amjad, A. Kamran, A. Hassan, and R. Karim, "A flexible antenna on cost-effective PEN substrate for sub-6 GHz 5G wireless transceivers," Proc. - 2019 Int. Conf. Front. Inf. Technol. FIT 2019, pp. 89-94, 2019.

[7] Y. Zhou, S. Sivapurapu, M. Swaminathan, and S. K. Sitaraman, "Mechanical and High-Frequency Electrical Study of Printed, Flexible Antenna under Deformation," IEEE Trans. Components, Packag. Manuf. Technol., vol. 10, no. 7, pp. 1088-1100, 2020.

[8] K. K. Naik, S. C. S. Teja, B. V. S. Sailaja, and P. A. Vijaya Sri, "Design of flexible parasitic element patch antenna for biomedical application," Prog. Electromagn. Res. M, vol. 94, no. March, pp. 143-153, 2020.

[9] M. Rizwan, M. W. A. Khan, H. He, J. Virkki, L. Sydänheimo, and L. Ukkonen, "Flexible and stretchable 3D printed passive UHF RFID tag," Electron. Lett., vol. 53, no. 15, pp. 1-2, 2017.

[10] A. S. M. Alqadami, M. F. Jamlos, P. J. Soh, and G. A. E. Vandenbosch, "Assessment of PDMS Technology in a MIMO Antenna Array," IEEE Antennas Wirel. Propag. Lett., vol. 15, pp. 1939-1942, 2016.

[11] D. P. Wang, Z. H. Zhao, C. H. Li, and J. L. Zuo, "An ultrafast selfhealing polydimethylsiloxane elastomer with persistent sealing performance," Mater. Chem. Front., vol. 3, no. 7, pp. 1411-1421, 2019.

[12] S. H. Cho, S. R. White, and P. V. Braun, "Room-temperature polydimethylsiloxane-based self-healing polymers," Chem. Mater., vol. 24, no. 21, pp. 4209-4214, 2012.

[13] M. Wehner et al., "An integrated design and fabrication strategy for entirely soft, autonomous robots," Nature, vol. 536, no. 7617, pp. 451455, 2016.

[14] Y. Bar-cohen, "Electroactive polymer (EAP) actuators — background review," Mech. Soft Mater., vol. 1:5, pp. 1-14, 2019.

[15] I. Cherukhin and G. Y. Xin, "Performance improvements in flexible polymer-based microwave devices," Asia-Pacific Microw. Conf. Proceedings, APMC, vol. 2019, pp. 619-621, 2019.

[16] I. Cherukhin, F. V. Zander, A. K. Dashkova, and Y. X. Guo, "Investigation of material properties for polymer-based microwave devices," J. Phys. Conf. Ser., vol. 1399, no. 4, 2019.

[17] I. Cherukhin, S. Gao, and Y. X. Guo, "Fully Flexible, Polymer-based Microwave Devices Part I: Materials, Fabrication Technique, and Application to Transmission Lines."

[18] A. Larmagnac, S. Eggenberger, H. Janossy, and J. Vörös, "Stretchable electronics based on Ag-PDMS composites," Sci. Rep., vol. 4, pp. 1-7, 2014.

[19] M. Park, J. Park, and U. Jeong, "Design of conductive composite elastomers for stretchable electronics," Nano Today, vol. 9, no. 2, pp. 244-260, 2014. 
[20] S. Ahmed, F. A. Tahir, A. Shamim, and H. M. Cheema, "A Compact Kapton-Based Inkjet-Printed Multiband Antenna for Flexible Wireless Devices," IEEE Antennas Wirel. Propag. Lett., vol. 14, pp. 1802-1805, 2015.

[21] M. A. Riheen, T. T. Nguyen, T. K. Saha, T. Karacolak, and P. K. Sekhar, "CPW fed wideband bowtie slot antenna on pet substrate," Prog. Electromagn. Res. C, vol. 101, no. March, pp. 147-158, 2020.

[22] H. Liu, S. Member, S. Zhu, P. Wen, X. Xiao, and W. Che, "Flexible CPW-Fed Fishtail-Shaped Antenna for Dual-Band Applications," IEEE Antennas Wirel. Propag. Lett., vol. 13, pp. 770-773, 2014.

[23] A. C. Durgun, S. Member, C. A. Balanis, L. Fellow, C. R. Birtcher, and D. R. Allee, "Design, Simulation, Fabrication and Testing of Flexible Bow-Tie Antennas," IEEE Trans. Antennas Propag., vol. 59, no. 12, pp. 4425-4435, 2011.

[24] A. Arayeshnia, A. Madannejad, J. Ebrahimizadeh, F. Ravanbakhsh, M. D. Perez, and R. Augustine, "Miniaturized CPW-fed bowtie slot antenna for wearable biomedical applications," 14th Eur. Conf. Antennas Propagation, EuCAP 2020, pp. 5-8, 2020.

[25] R. B. V. B. Simorangkir, Y. Yang, K. P. Esselle, and B. A. Zeb, "A method to realize robust flexible electronically tunable antennas using polymer-embedded conductive fabric," IEEE Trans. Antennas Propag., vol. 66, no. 1, pp. 50-58, 2018.

[26] Y. Song, D. Le Goff, G. Riondet, and K. Mouthaan, "Polymer-based 2.4 GHz patch antenna," 2020 Int. Work. Antenna Technol. iWAT 2020, pp. $7-10,2020$.

[27] M. Rizwan, M. W. A. Khan, L. Sydanheimo, J. Virkki, and L. Ukkonen, "Flexible and stretchable brush-painted wearable antenna on a threedimensional (3-D) printed substrate," IEEE Antennas Wirel. Propag. Lett., vol. 16, pp. 3108-3112, 2017.

[28] A. S. M. Sayem, K. P. Esselle, and R. M. Hashmi, "Robustness Analysis of the Polymer-Conductive-Mesh Composite for the Realization of Transparent and Flexible Wearable Antennas," 14th Eur. Conf. Antennas Propagation, EuCAP 2020, pp. 1-4, 2020.

[29] R. Sahoo and D. Vakula, "Bow-tie-shaped wideband conformal antenna with wide-slot for GPS application," Turkish J. Electr. Eng. Comput. Sci., vol. 27, no. 1, pp. 80-93, 2019.

[30] M. O. Sallam, S. M. Kandil, V. Volski, G. A. E. Vandenbosch, and E. A. Soliman, "Wideband CPW-Fed Flexible Bow-Tie Slot Antenna for WLAN/WiMax Systems," IEEE Trans. Antennas Propag., vol. 65, no. 8, pp. 4274-4277, 2017.

[31] M. F. Farooqui and A. Shamim, "Dual band inkjet printed bow-tie slot antenna on leather," 2013 7th Eur. Conf. Antennas Propagation, EuCAP 2013, pp. 3287-3290, 2013. 